$\xi-$

\title{
Functional time series analysis of age-specific fertility rates: visualizing the change in the age-pattern of fertility in India
}

\author{
Mallika Deb*, Tapan Kumar Chakrabarty \\ Department of Statistics, North-Eastern Hill University, East Khasi Hills, Shillong, Meghalaya, 793022, India \\ *Corresponding author E-mail: mallikadeb706@gmail.com
}

\begin{abstract}
Functional Time Series Analysis (FTSA) is carried out in this article to uncover the temporal variations in the age pattern of fertility in India. Attempt is made to find whether there is any typical age pattern in the nation's fertility across the reproductive age groups. If so, how do we characterize the role of changing age pattern of fertility across reproductive age groups in the nation's fertility transition? We have used region-specific (rural-urban) and country level data series on Age-Specific Fertility Rates (ASFRs) available from Sample Registration System (SRS), India during 1971-2013. Findings of this study are very impressive. It is observed that the youngest age group of women in 15-19 years has contributed to the maximum decline in fertility with a substantially accelerated pace during the period of study. The major changes in fertility rates among Indian women dominated by the rural representation occur at the ages after 30 . Further, the study also suggests that the future course of demographic transition in India from third phase to the fourth phase of replacement fertility would depend on the degree and pace of decline among the rural women aged below 30 years.
\end{abstract}

Keywords: Age-Specific Fertility Rates; Cubic Spline Interpolation Smoothing; Fertility Forecasting; Functional Time Series Analysis; Principal Component.

\section{Introduction}

Functional data arise in many diverse fields ranging from archaeology, economics, criminology, psychology to the newer fields of computer science, electronics, medicine, biomedicine, public health etc. Data or information that come in the form of functions, curves, surfaces etc. varying over a continuum are called functional data. The continuum, for instance, may be time, location, wavelength, probability and so on. The technological advancements in measurement, collection and storage of data have led to the availability of functional data. Such data, although recorded in a discrete fashion, are usually thought of as continuous objects represented by functional relationships. This gives rise to functional data analysis (FDA), made popular by the monographs of Ramsay and Silverman (1997 [13], 2002 [14]), where the center of interest is a set of curves, shapes, objects, or, more generally, a set of functional observations. This is in contrast to classical statistics where the interest centers around a set of data vectors. In that sense, functional data is not only different from the data-structure studied in classical statistics, but it actually generalizes it. Many of these new data-structures call for new statistical methods in order to unveil the information that they carry. FDA extends existing methodologies and theories from the areas of functional analysis, generalized linear models, multivariate data analysis, nonparametric smoothing, stochastic process, and many others. Ramsay and Silverman (2005) [15] and Ferraty and Vieu (2006) [5] provide detailed surveys of many parametric and nonparametric techniques for analyzing functional data.

The presence of functional data in modelling and analysis of time series has started to receive attention, particularly in terms of its public health and biomedical applications. When the same func- tional object is observed over a period of time, such data are known as functional time series. Commonly, time series data are treated as multivariate data because they are given as a finite discrete time series. This usual multivariate approach completely ignores important information about the smooth functional behavior of the generating process that underpins the data (Green and Silverman, 1994 [6]). It also suffers from issues associated with highly correlated measurements within each functional object. The basic idea behind FDA is to express discrete observations arising from time series in the form of a function (to create functional data) that represents the entire measured function as a single observation, and then to draw modeling and/or prediction information from a collection of functional data by applying statistical concepts from multivariate data analysis. In doing so, it has the advantage of generating models that can be described by continuous smooth dynamics, which then allow for accurate estimates of parameters for use in the analysis phase, effective data noise reduction through curve smoothing, and applicability to data with irregular time sampling schedules.

Ramsay and Dalzell (1991) [12], present several practical reasons for considering functional data:

1. smoothing and interpolation procedures can yield functional representations of a finite set of observations;

2 . it is more natural to think through modelling problems in a functional form; and

3. the objectives of an analysis can be functional in nature, as would be the case if finite data were used to estimate an entire function, its derivatives, or the values of other functionals.

Modelling, estimation and forecasting functional time series is termed as functional time series analysis analyzing functional time 
series has received increasing attention in the functional data analysis literature (see for example, Besse and Cardot, 2000 [1]; Hormann and Kokoszka, 2010 [7]; Hyndman and Shang, 2010 [11]; Shang 2013 [20]). Hyndman and Ullah (2007) [8] proposed for forecasting age-specific mortality and fertility rates observed over time. This approach allows for smooth functions of age, is robust for outlying years due to wars and epidemics, and provides a modelling framework that is easily adapted to allow for constraints and other information. Ideas from functional data analysis, nonparametric smoothing and robust statistics are combined to form a methodology that is widely applicable to any functional time series data observed discretely and possibly with error. The model is a generalization of the Lee-Carter (LC) model commonly used in mortality and fertility forecasting.

Over the last decade, numerous applications of FTSA which are the modifications of Hyndman-Ullah method, can be found in different fields of research, such as demographic modelling and forecasting (Hyndman and Booth, 2008 [9]; Hyndman and Shang, 2009 [10]; Yasmeen, Waseem and Mahmood, 2014 [23]), climate forecasting (Shang and Hyndman, 2011 [21]) etc. Hyndman and Booth (2008) [9] used the general Box-cox transformation to minimize out-of-sample forecast error.

Hyndman and Shang (2009) [10] proposed forecasting functional time series using weighted functional principal component regression and weighted functional partial least squares regression. These approaches allow for smooth functions, assign higher weights to more recent data, and provide a modelling scheme that is easily adapted to allow for constraints and other information. They illustrated their approaches using age-specific French female mortality rates, which is another improvement of FTSA. Shang and Hyndman (2011) [21] proposed a nonparametric method to forecast a seasonal univariate time series, and propose several dynamic updating methods to improve point forecast accuracy. Their methods consider a seasonal univariate time series viz. monthly sea surface temperatures as a functional time series.

The broad Indian fertility scenario is well known and the country which is currently passing through the third phase of demographic transition with a substantial accelerated fertility decline, has not yet reached the population stabilizing replacement level (Chakrabarty and Deb, 2015 [4]). It is argued that the country's fertility rate often masks the wide disparities by state and regional level vital statistics. Several studies have been carried out towards this goal including those of Spoorenberg and Dommaraju (2012) [22], Ratherford and Mishra (2001) [16] etc. Not many works, however, are found in the nation's fertility study literature, exclusively exhibiting the role of changing age pattern of fertility for fertility transition of the country. With the advent of FTSA tool and the availability SRS data archive, it is possible for us to address whether the changes and fluctuations in the age pattern of fertility across various reproductive age groups have substantially affected the overall fertility scenario in the country. In particular, this paper aims at probing the following issues. First, is there any typical age pattern in the nation's fertility across the reproductive age groups? If so, how do we visualize the pattern and the degree of differences? Second, how do we characterize the role of chang ing age pattern of fertility across reproductive age groups in the nation's fertility transition? Have the higher fertile age groups substantially contributed to the pace and timing of fertility decline?

The paper is organized in the following manner. Section 2 deals in defining and explaining the typical terms for the data used and the data structure. Section 3 analyzes the comparative pace of fertility decline across various reproductive age groups. Section 4 describes the FTSA methodology in present set up and the analysis has been done using the statistical software 'R-3.1.3'. Section 5 is devoted to the analysis of data and results. The article concludes with section 6 .

\section{Data}

In this article, we use time series data on ASFR from Sample Registration System, Registrar General of India (RGI $[17,18]$ ), which is a large scale demographic survey for providing annual and reliable estimates of vital rates at region and national level by the Office of The Registrar General, India. ASFR is the number of live births per 1000 women in a specific five year age group for a specified geographical area and for a specific point in time, usually a calendar year. It is usually calculated for five year age categories $15-19,20-24 \ldots$ 45-49.

Symbolically,

ASFR $=\frac{\text { Number of live births to women in specified age group }}{\mathrm{Number} \text { of } \text { women in same age group }}$ 1000

$n^{f}{ }_{x}=\frac{n^{B} x}{n^{W}} \times 1000$

Here, $\mathrm{n}=5 ; \mathrm{x}=15-19,20-24 \ldots 45-49, n^{f}{ }_{x}$ is the age specific fertility rate of women aged $\mathrm{x}$ to $(x+n)$ years, $n^{B}{ }_{x}$ is the number of live births in a year to the women of ages $\mathrm{x}$ to $(x+n)$ years in a given years and geographical region and $n_{x}^{W}$ is the number of women aged $\mathrm{x}$ to $(x+n)$ years at mid-year in a given year and geographical area.

Statistical reports published by SRS have been providing reliable estimates of fertility and mortality on a regular basis since 1971 . These include data on population composition by broad age groups, sex and marital status, fertility and mortality levels, for India and bigger States (with population 10 million and above) separately for rural and urban areas. The present analysis has been carried out using estimates of ASFR for the five year age categories as mentioned above from 1971 to 2013. The estimates are available for 1971, 1976, 1980, 1981 and 1986-2013 at the country level and for 1971, 1976, 1981, 1984 and 1986-2013 at regional (rural and urban) level. ASFRs are missing for rest of the years, so we estimated those applying cubic spines interpolation method using Rpackage 'stats'. The estimated missing values are provided in Appendix (Table A1, Table A2 and Table A3).

\section{Pace of fertility decline in India across re- productive age group}

The estimated age-specific fertility rates of India (total, rural and urban) are viewed as univariate time series in Fig. 1 to see the age pattern of fertility decline across the reproductive age groups. The figure depicts the competitiveness in the pattern and extent of fertility change in the major age categories at the national as well as at regional levels. It shows that for all three cases the most fertile age group is 20-24 and the trend in ASFR for this group remained turbulent for the entire period and more specifically during post 1990. However, the urban ASFR remained much below that of the rural for the entire period. This statement is relevant across all the age groups. Since India is a country dominated by rural population, so is its age pattern of fertility dominated by the rural pattern. Also, for most of the age categories, the ASFRs we can see that the total and rural region have smoother fertility decline than that of urban.

Two important features of fertility schedule as depicted by the figure are noteworthy. First, except the age categories 20-24 and 25-29 all are declining very fast towards the replacement level. Second, there is a sudden increase ASFRs in teen age group (1519) along with the most fertile age group (20-24) from 1975 to 1995 for total and rural area. Urban region of the country also experienced a relatively smaller degree of acceleration in the teen age fertility during 1980 to 1995 . Thus the country has experienced a substantial rise in the age at marriage after 1995. Consequently, the most fertile age category has witnessed frequent fluctuations and turbulence in ASFRs during 1995-2013. 
Time Series Plot of ASFR (Total)

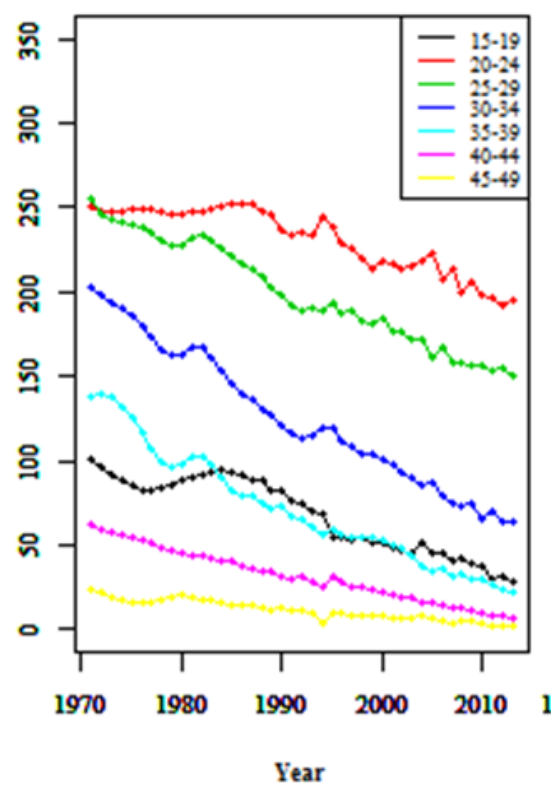

Time Series Plot of ASFR (Rural)

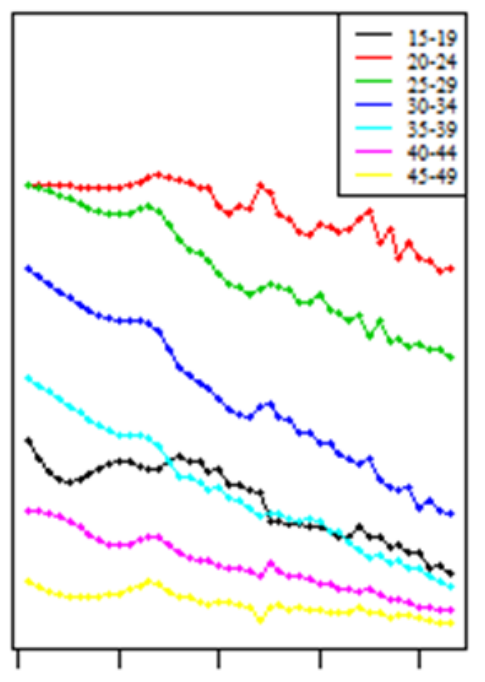

Year
Time Series Plot of ASFR (Urban)

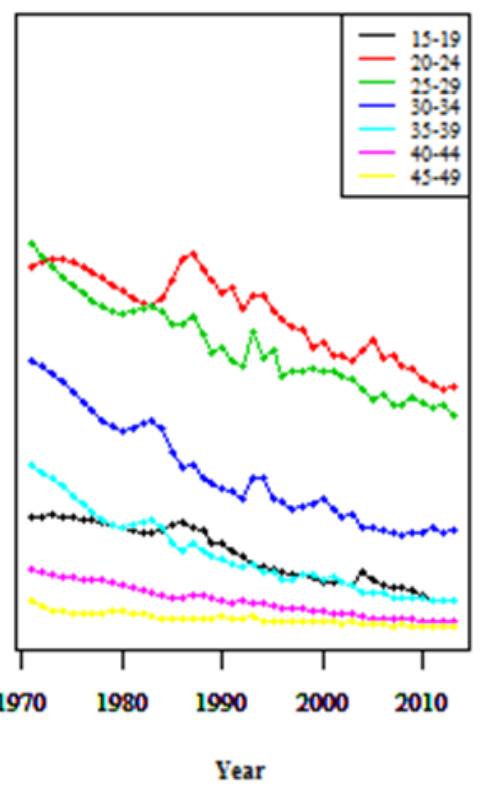

Figure 1: Fertility Rates in India (Total, Rural and Urban) from 1971 to 2013 viewed as univariate time series ages 15-49.

While during the early seventies, the age categories 20-24 and 2529 , both remained highest fertile simultaneously for some years for rural as well as for the entire nation, urban India witnessed 2529 as the most fertile till 1972 or so. Hence, we can say that the peak of fertility has shifted from the age group 25-29 to 20-24 by 1972 for the urban India which is demonstrated from the estimated ASFRs. Again there was a tendency to change the peak at 1983 in urban region but it could not carry on. Hence, after 1983 there is no evidence of peak shifting in the age-pattern of fertility in India.

Fig. 1 exhibits differential pattern and differential pace of fertility decline across all the age categories. So, with a view to assess the differential pace of fertility decline in rural-urban fertility schedules over each of the last four decades across reproductive agegroups we adopt the following methodology (Chakrabarty, 2014 [3]). Let, $F_{t}(x)$ be the value of ASFR in the year $t$ for a given age group x. The Annual Rate of Reduction (ARR) from year t-1 to year $\mathrm{t}$ for a given $\mathrm{x}$ is defined as,

$\operatorname{ARR}_{\mathrm{t}}(\mathrm{x})=\frac{\mathrm{F}_{\mathrm{t}-1}(\mathrm{x})-\mathrm{F}_{\mathrm{t}}(\mathrm{x})}{\mathrm{F}_{\mathrm{t}-1}(\mathrm{x})} * 100$

So that average ARR (AARR) over a period can be obtained by taking just the arithmetic mean of these $\operatorname{ARR}_{t}(x)$ 's. For instance, AARR(x) over the period 1971-81 for a given $\mathrm{x}$, can be obtained as,

$\operatorname{AARR}_{1971-81}(x)=\frac{\sum_{t=1972}^{1981} \operatorname{ARR}_{t}(x)}{10}$

Table 1 above calculates AARR for several periods in order to show the pace of decline in fertility across various reproductive age-groups in India including its rural and urban components. Accordingly, Fig. 2 displays the varying pattern of the pace of decline over the period 1971-2011.
Table 1: Level of fertility decline among reproductive age groups in India (Total, Rural and Urban)

\begin{tabular}{cccccc}
\hline \multicolumn{5}{c}{ Average Annual Rate of Reduction } \\
\hline Total & $\mathbf{1 9 7 1 - 8 1}$ & $\mathbf{1 9 8 1 - 9 1}$ & $\mathbf{1 9 9 1 - 0 1}$ & $\mathbf{2 0 0 1 - 1 1}$ & $\mathbf{1 9 7 1 - 1 1}$ \\
$\mathbf{1 5 - 1 9}$ & 1.04 & 1.64 & 4.17 & 4.26 & 2.78 \\
$\mathbf{2 0 - 2 4}$ & 0.16 & 0.53 & 0.77 & 0.86 & 0.58 \\
$\mathbf{2 5 - 2 9}$ & 0.92 & 1.91 & 0.74 & 1.39 & 1.24 \\
$\mathbf{3 0 - 3 4}$ & 1.84 & 3.53 & 1.67 & 3.24 & 2.57 \\
$\mathbf{3 5 - 3 9}$ & 2.83 & 4.14 & 2.81 & 6.01 & 3.95 \\
$\mathbf{4 0 - 4 4}$ & 3.40 & 3.53 & 3.22 & 8.28 & 4.61 \\
$\mathbf{4 5 - 4 9}$ & 1.88 & 4.44 & -3.17 & 7.63 & 2.69 \\
$\mathbf{R u r a l}$ & $\mathbf{1 9 7 1 - 8 1}$ & $\mathbf{1 9 8 1 - 9 1}$ & $\mathbf{1 9 9 1 - 0 1}$ & $\mathbf{2 0 0 1 - 1 1}$ & $\mathbf{1 9 7 1 - 1 1}$ \\
$\mathbf{1 5 - 1 9}$ & 1.07 & 1.42 & 3.77 & 4.22 & 2.62 \\
$\mathbf{2 0 - 2 4}$ & -0.02 & 0.65 & 0.28 & 0.80 & 0.43 \\
$\mathbf{2 5 - 2 9}$ & 0.66 & 1.88 & 0.75 & 1.26 & 1.14 \\
$\mathbf{3 0 - 3 4}$ & 1.62 & 3.30 & 1.56 & 3.53 & 2.50 \\
$\mathbf{3 5 - 3 9}$ & 2.66 & 3.81 & 2.76 & 5.95 & 3.80 \\
$\mathbf{4 0 - 4 4}$ & 3.34 & 2.95 & 2.44 & 8.00 & 4.18 \\
$\mathbf{4 5 - 4 9}$ & 1.49 & 3.86 & -6.63 & 6.39 & 1.27 \\
Urban & $\mathbf{1 9 7 1 - 8 1}$ & $\mathbf{1 9 8 1 - 9 1}$ & $\mathbf{1 9 9 1 - 0 1}$ & $\mathbf{2 0 0 1 - 1 1}$ & $\mathbf{1 9 7 1 - 1 1}$ \\
$\mathbf{1 5 - 1 9}$ & 1.09 & 2.17 & 5.33 & 3.81 & 3.10 \\
$\mathbf{2 0 - 2 4}$ & 0.91 & -0.35 & 2.12 & 1.09 & 0.94 \\
$\mathbf{2 5 - 2 9}$ & 1.95 & 1.58 & 0.33 & 1.50 & 1.34 \\
$\mathbf{3 0 - 3 4}$ & 2.88 & 3.49 & 1.29 & 1.53 & 2.29 \\
$\mathbf{3 5 - 3 9}$ & 4.60 & 4.35 & 1.81 & 5.35 & 4.03 \\
$\mathbf{4 0 - 4 4}$ & 3.51 & 4.68 & 4.49 & 8.53 & 5.30 \\
$\mathbf{4 5 - 4 9}$ & 4.76 & 4.33 & 2.98 & 6.55 & 4.65 \\
\hline & & & & & \\
\hline
\end{tabular}

Above analysis suggests that during the course of the transition, the age-pattern of fertility has changed substantially. First, an impressive rise in the average annual rate of reduction in ASFR has been seen in the young ages especially 15-19 after 1991. Such a rise in the pace of fertility decline is attributed to the rise in the age of marriage both in rural and urban India. The pace of decline in the most fertile age group 20-24 has remain below one percent for the entire period in rural as well as for the entire country which is mostly on account of rise in the age at marriage. The urban India on the other hand has experienced an increase more than two percent of AARR in the age group 20-24 during 1991-01. The fertility pattern for the three mid-age-categories remained similar for the entire period 1971-2011 which is evident due to the presence of parallel trend lines as depicted in Fig. 1. Moreover, the pace of decline is also closely followed by one another. It is inter- 
esting to note that in all the three above mentioned age-categories AARR failed by 1-2 percent during 1991-2001 and also followed by an increase of about the same amount during 2001-11. Fertility at ages beyond 30 years of age fell sharply with rise in AARR from three to eight percent during 2001-11, and beyond 40 years, by over seven percent. As a result, fertility is now highly concentrated in the age groups of 20-24 and 25-29.

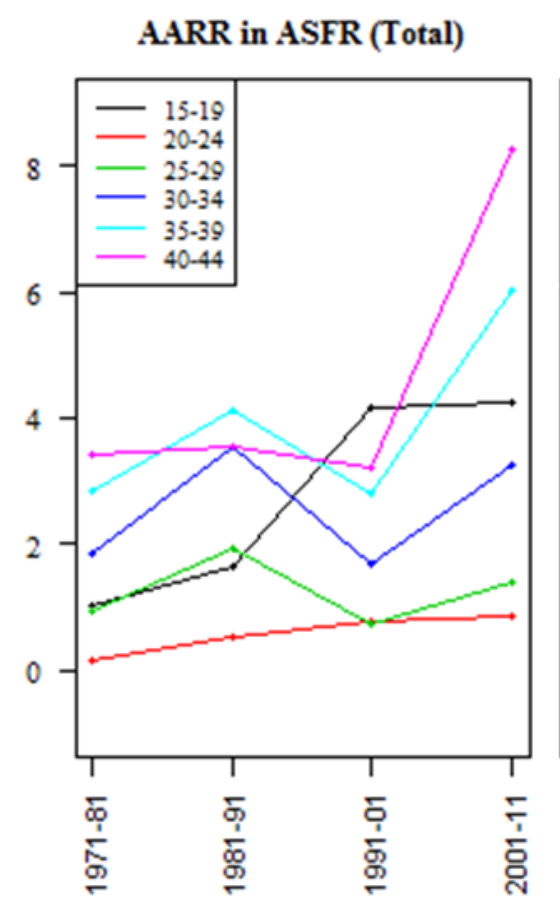

AARR in ASFR (Rural)

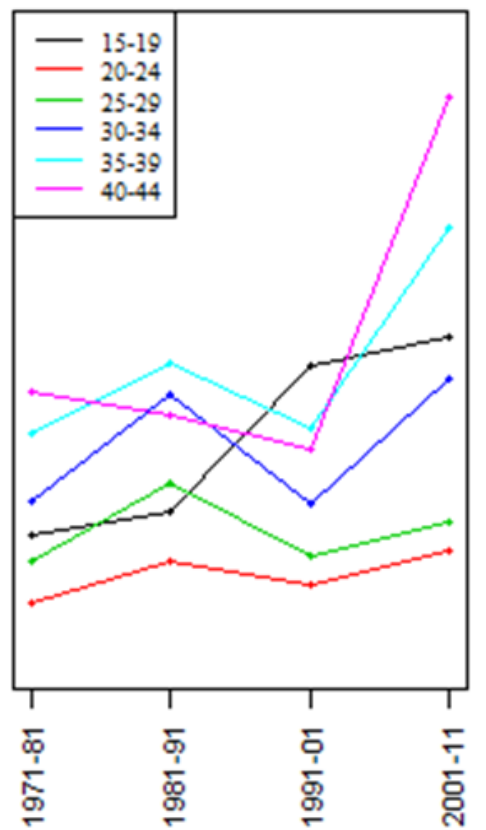

AARR in ASFR (Urban)

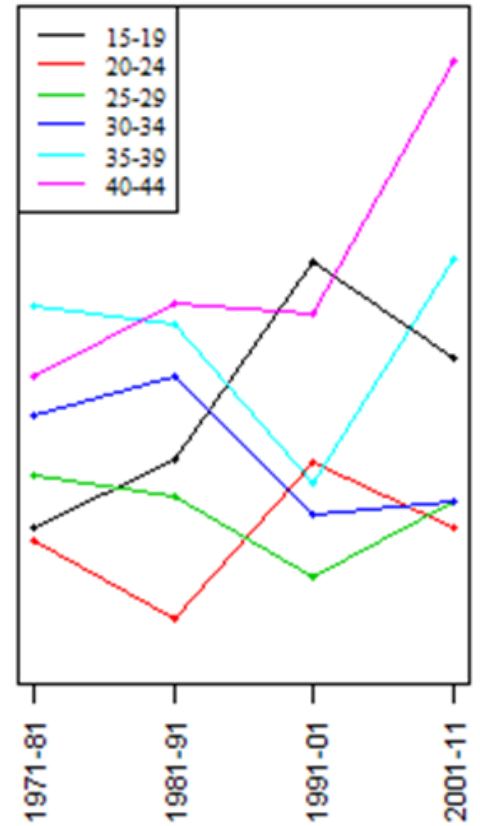

Figure 2: Decadal pace of fertility decline among reproductive age groups during 1971-2011.

\section{FTSA Methodology}

In this article, we have adopted the methodology as proposed by Hyndman and Ullah (2007) [8] to analyze and forecast ASFRs that combine ideas from functional data analysis and nonparametric smoothing. This technique uses principal component decomposition and so it is also called Functional Principal Component Analysis (FPCA). It treats the underlying process as functional and provides estimation and forecasting. Let, $\mathrm{y}_{\mathrm{t}}(\mathrm{x})$ denote the observed fertility rate of age $x$ in year $t$. We assume that there is an underlying smooth function $\mathrm{f}_{\mathrm{t}}(\mathrm{x})$ that we are observing with error and at discrete points of $\mathrm{x}$. Our observations are, $\left\{\mathrm{x}_{\mathrm{i}}, \mathrm{y}_{\mathrm{t}}\left(\mathrm{x}_{\mathrm{i}}\right)\right\}, \mathrm{t}=1$, $2 \ldots \mathrm{n} ; \mathrm{i}=1,2 \ldots \mathrm{p}$ where

$\mathrm{y}_{\mathrm{t}}\left(\mathrm{x}_{\mathrm{i}}\right)=\mathrm{f}_{\mathrm{t}}\left(\mathrm{x}_{\mathrm{i}}\right)+\sigma_{\mathrm{t}}\left(\mathrm{x}_{\mathrm{i}}\right) \varepsilon_{\mathrm{t}, \mathrm{i}}$

$\varepsilon_{\mathrm{t}, \mathrm{i}}$ is an i.i.d standard normal random variable and $\sigma_{\mathrm{t}}\left(\mathrm{x}_{\mathrm{i}}\right)$ allows the amount of noise to vary with $\mathrm{x}_{\mathrm{i}}$. The set $\mathrm{X}=\left\{x_{1}, x_{2} \ldots x_{p}\right\}$ denote 5-year age groups $\left(\mathrm{x}_{1}=15-19, \mathrm{x}_{2}=20-24 \ldots \mathrm{x}_{\mathrm{p}}=45-49\right)$ in this paper. We are interested in forecasting $\mathrm{y}_{\mathrm{t}}(\mathrm{x})$ for $\mathrm{x} \in \mathrm{X}$ and $\mathrm{t}$ $=(n+1),(n+2) \ldots(n+h)$.

The approach is summarized below:

1. Smooth the data for each $t$ using a Cubic-Spline Interpolation smoothing method using R-package 'stats' to estimate $\mathrm{f}_{\mathrm{t}}(\mathrm{x})$ for $\mathrm{x} \in \mathrm{X}$ from $\left\{\mathrm{x}_{\mathrm{i}}, \mathrm{y}_{\mathrm{t}}\left(\mathrm{x}_{\mathrm{i}}\right)\right\}, \mathrm{t}=1,2 \ldots \mathrm{n} ; \mathrm{i}=1$, 2 ...p.
2. Decompose the fitted curves via a basis function expansion using the following model:

$f_{t}(x)=\mu(x)+\sum_{k=1}^{K} \beta_{t, k} \phi_{k}(x)+e_{t}(x)$

where, $\mu(x)$ is the mean fertility rate across years i.e. a measure of location of $\mathrm{f}_{\mathrm{t}}(\mathrm{x}),\left\{\phi_{\mathrm{k}}(\mathrm{x})\right\}$ is a set of $\mathrm{K}$ orthogonal basis functions or principal component functions and $\left\{\beta_{\mathrm{t}, \mathrm{k}}\right\}$ is a set of corresponding principal component scores estimated using principal component decomposition and $\mathrm{e}_{\mathrm{t}}(\mathrm{x}) \sim$ i.i.d. $\mathrm{N}(0, \mathrm{v}(\mathrm{x}))$. $\phi_{\mathrm{k}}(\mathrm{x})$ 's are computed using functional components applied to the smooth curves $\mathrm{f}_{\mathrm{t}}(\mathrm{x})$.

3. $\left\{\beta_{\mathrm{t}, \mathrm{k}}\right\}$ are uncorrelated so it can be fitted univariate time series models to each of the coefficients $\left\{\beta_{\mathrm{t}, \mathrm{k}}\right\}$ independently, $\mathrm{k}=1,2 \ldots \mathrm{K}$.

4. Forecast the coefficients $\left\{\beta_{\mathrm{t}, \mathrm{k}}\right\}, \mathrm{k}=1,2 \ldots \mathrm{K}$, for $\mathrm{t}=$ $(n+1),(n+2) \ldots(n+h)$ using the fitted time series models (Box and Jenkins, 1976 [2]).

5. By multiplying the forecasted coefficients with Eigen vectors from Equation (3) forecasts of $\mathrm{f}_{\mathrm{t}}(\mathrm{x}), \mathrm{t}=(n+$ $1),(n+2) \ldots(n+h)$ can be obtained. From Equation (2), forecasts of $\mathrm{f}_{\mathrm{t}}(\mathrm{x})$, are also forecasts of $y_{t}(x)$.Symbolically, the h-step ahead forecast of $\mathrm{y}_{\mathrm{n}+\mathrm{h}}(\mathrm{x})$ can be obtained as,

$\widehat{y_{n, h}(x)}=E\left(y_{t+h}(x)\right)=\widehat{\mu(x)}+\sum_{k=1}^{K} \widetilde{\beta_{n, k, h}} \widehat{\phi_{k}(x)}$ 
where $\widehat{\mu(\mathrm{x})}$ and $\widehat{\phi_{k}(x)}$ are the estimates of the mean function and basis functions respectively and $\widetilde{\beta_{n, k, h}}$ denote the h-step forecast

\section{Results and Discussion}
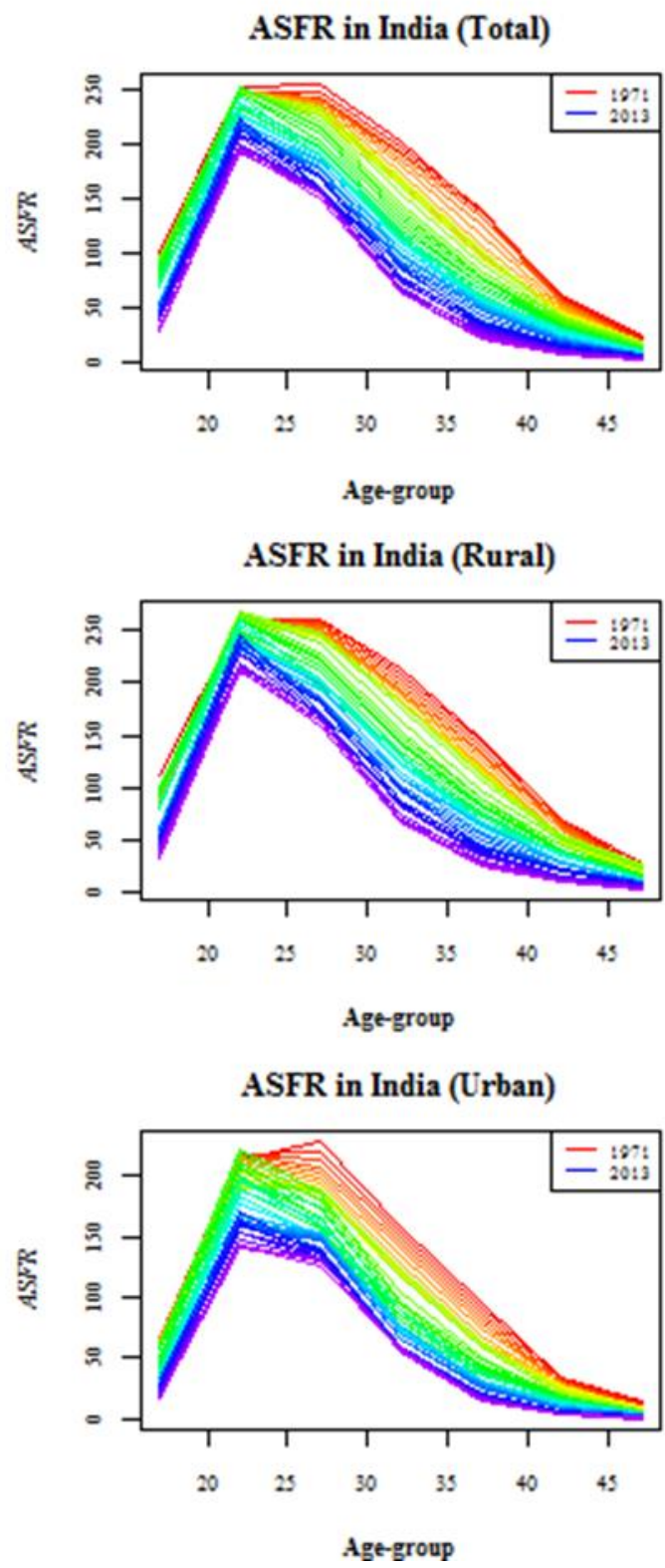

of $\beta_{n+h, k}$.

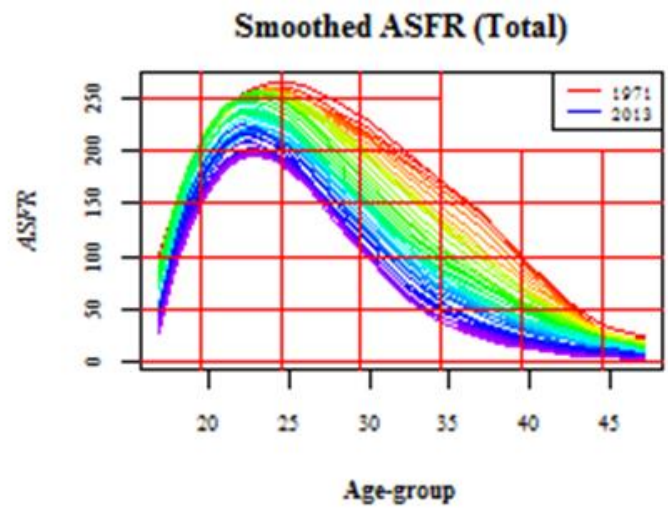

Smoothed ASFR (Rural)

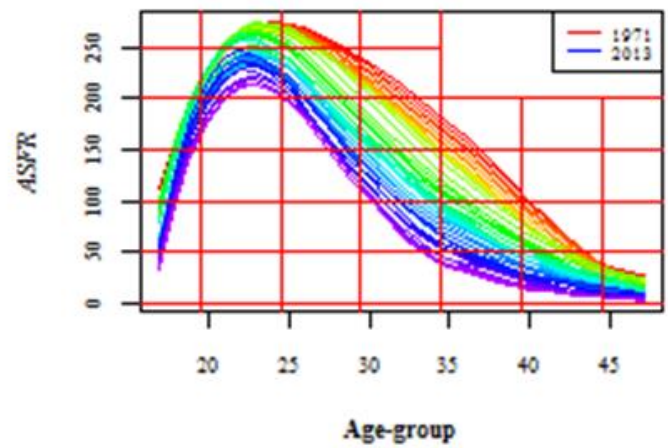

Smoothed ASFR (Urban)

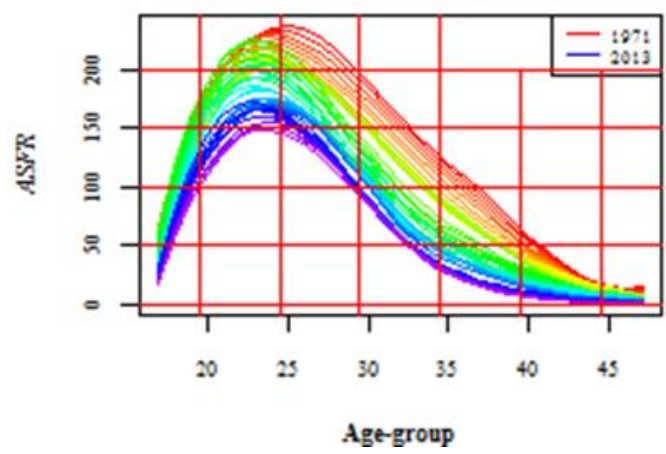

Figure 3: Fertility Rates in India (Total, Rural and Urban) observed and smoothed data from 1971 to 2013 viewed as functional time series ages $15-49$.

The observed and smoothed ASFRs of India (Total, Rural and Urban) are displayed as functional time series in Fig. 3 during the period 1971-2013 of study. The plots are created using the $r$ package 'ftsa' (Hyndman and Shang, 2010 [11]; Shang, 2011 [19]; Shang, 2013 [20]). Fig. 3 demonstrates the pattern of ASFR for rural and urban areas of India during the study period 1971-2013. The bands of smooth curves provide the evidence of fertility decline across all the reproductive age groups with temporal and regional variability. Approximately for each year, the standard shape depict the age pattern of fertility with increasing values for 15-19 years which rise to a maximum between 20-29 and decreasing after the age of 30 years. From the functional view of ASFR it is also evident that there has been a peak shifting somewhere in between 1970 to 1975, most likely at 1972, when the country witnessed the age-category $20-24$ as the most fertile one in place of the age-category 25-29. Functional visualization also demonstrates the regional disparities in temporal variations of ASFRs over the study period. Women from urban India below 30 years of age have shown wider variability in fertility in comparison to their counter parts in rural area over the study period 1971-2013. On the other hand, rural women above 30 years of age had shown wider temporal variations during the same period. This describes the evolution of the process of fertility transition in India, which was initiated at the urban part of the country and then gradually extended to the rural area. Moreover, if we compare green and violate lines (recent years), there is a slight rise in higher age fertility which may be attributed to the increased interest in education and the trend to postpone raising children in exchange for career pursuit.

Also there is a significant similarity between total and rural fertility transition which is an indication of India is a rural-based country. For instance, in India entirely and for rural region, there is a huge variability in older age groups viz. 30-34, 35-39, 40-44 and 
45-49 is more than younger age groups viz. 15-19, 20-24 and 2529 and for urban region variability is slightly more in older age groups than younger otherwise for urban region the variability is almost uniform in 25-39 that means old-aged women are not taking chances to give birth now-a-days compared to 1970's in total and rural and vice versa for urban India. Using functional time series models we have obtained the forecasts for next ten years (2014-2023) in India as a whole including rural and urban region.

To decide the number of basis functions needed for modelling the functional data, it is essential to know the percentages of variances explained by each basis functions and here we considered only first five basis functions. So, the scree plot is shown in Fig. 4.

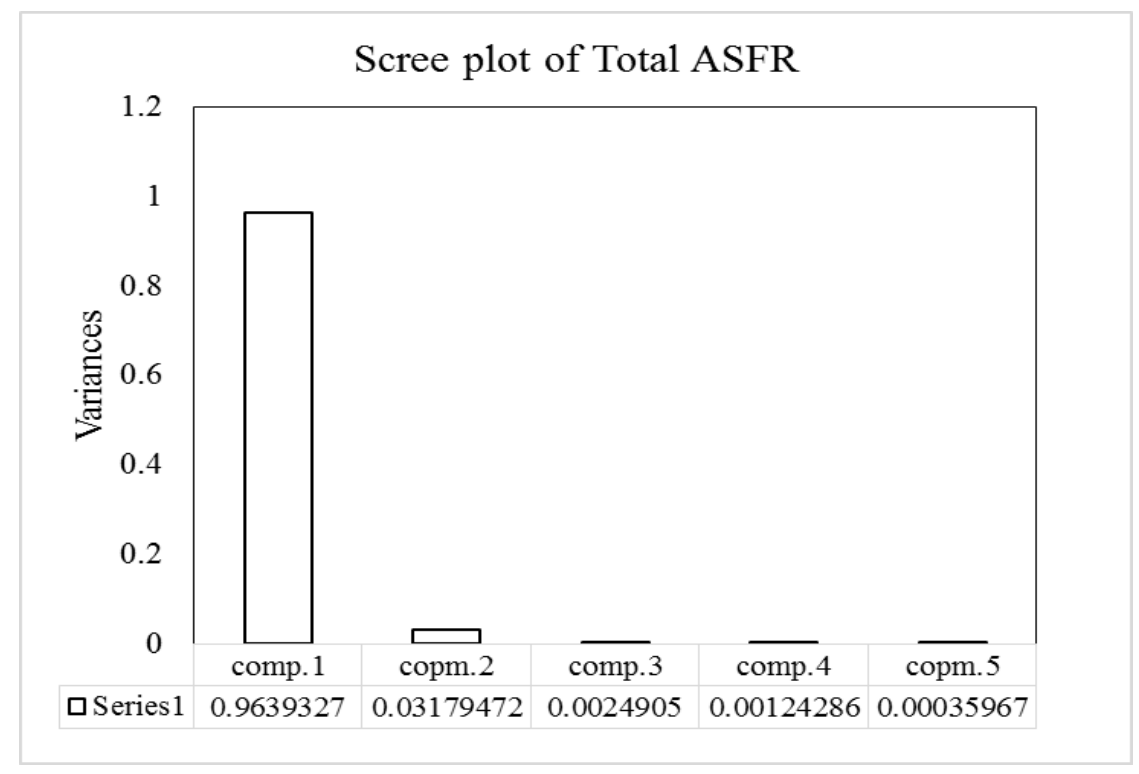

Figure 4: Percentages of variances explained by each components.

Main effects

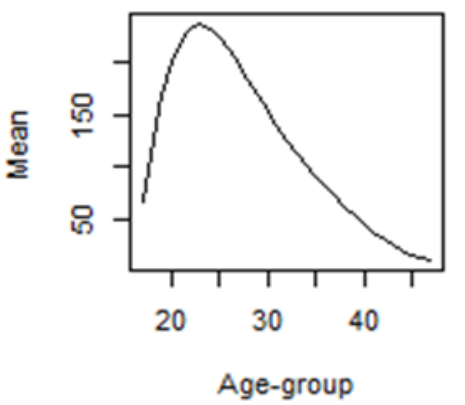

Age-group
Interaction
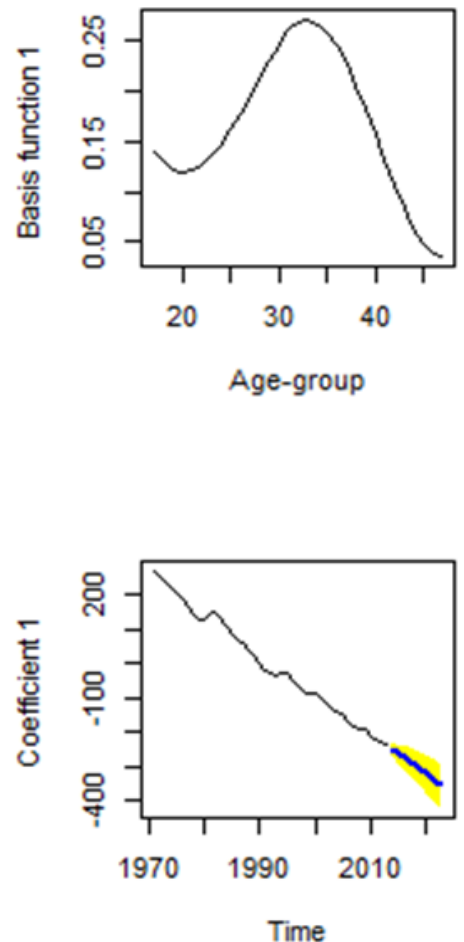
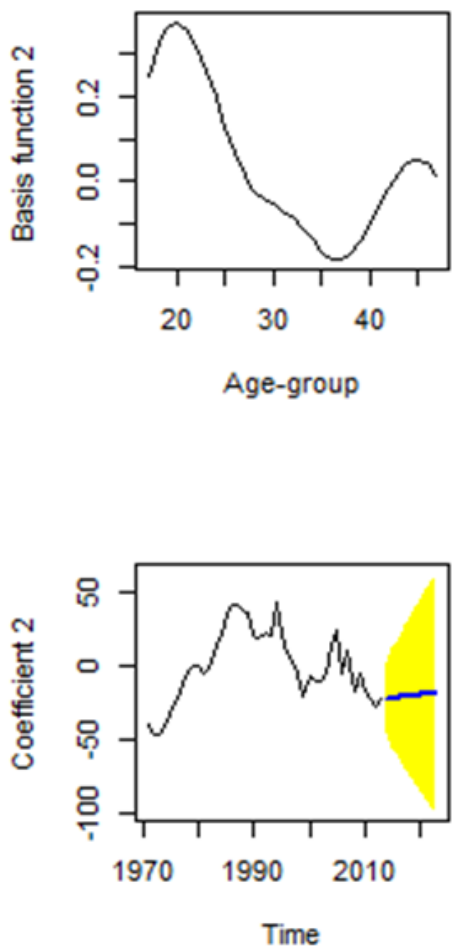

Figure 5: Essential basis functions and associated coefficients and forecasts of the coefficients from 2014 to 2023 are shown with $95 \%$ prediction intervals for India as a whole. 


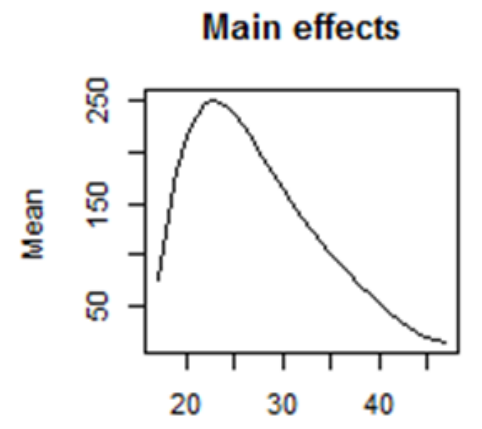

Age-group

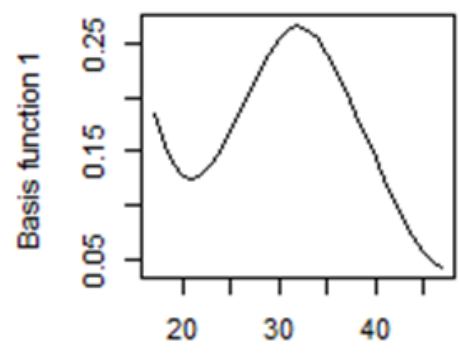

Age-group

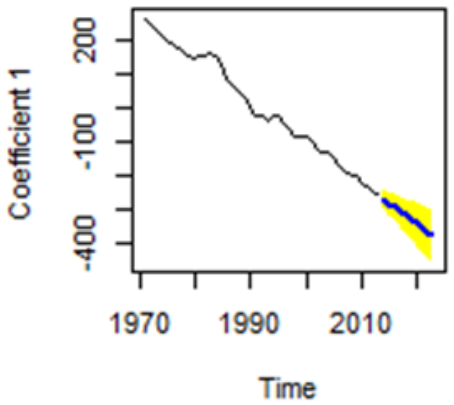

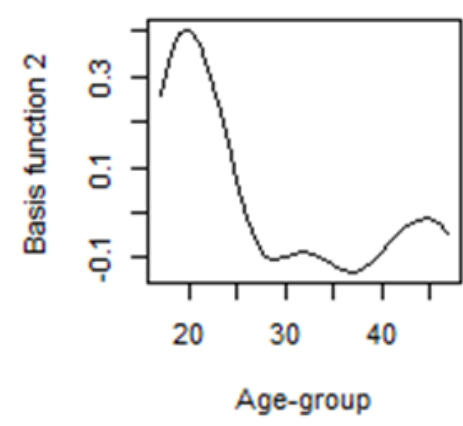

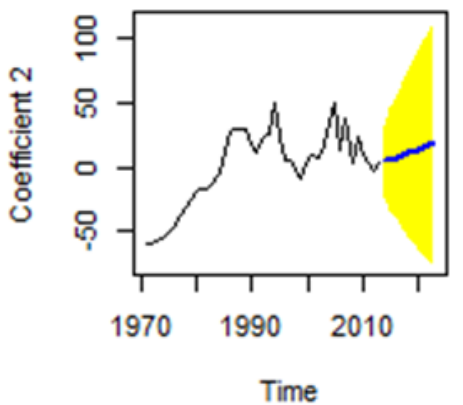

Figure 6: Essential basis functions and associated coefficients and forecasts of the coefficients from 2014 to 2023 are shown with $95 \%$ prediction intervals for rural India.

Main effects

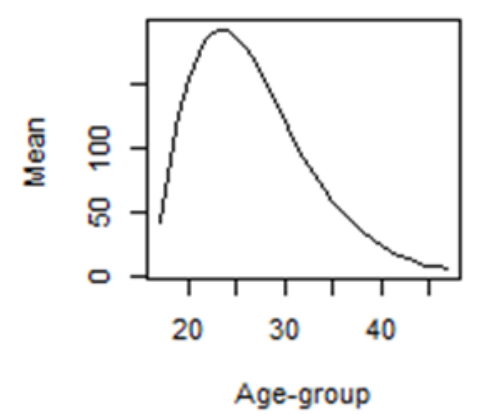

Age-group
Interaction
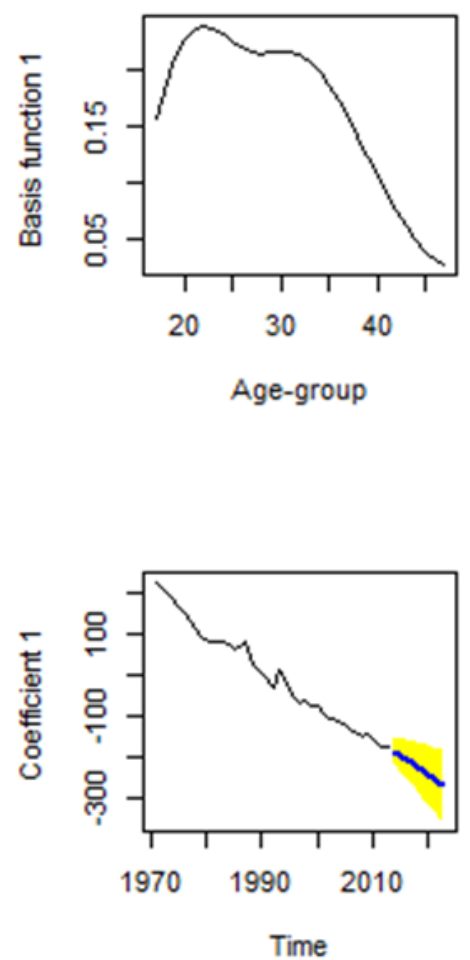
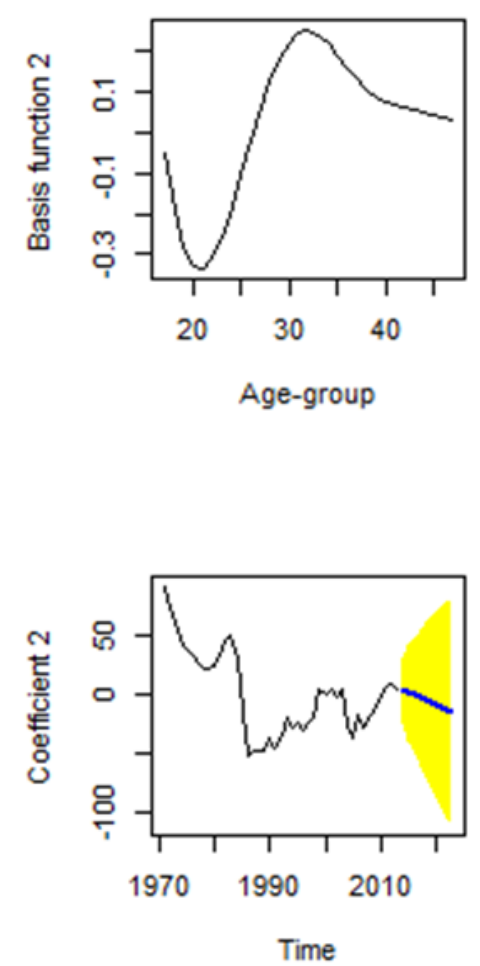

Figure 7: Essential basis functions and associated coefficients and forecasts of the coefficients from 2014 to 2023 are shown with $95 \%$ prediction intervals for urban India. 
Table 2: Forecast values of ASFR along with 95\% prediction interval for whole India

\begin{tabular}{|c|c|c|c|c|c|c|c|}
\hline Forecast (Total) & $15-19$ & 20-24 & 25-29 & 30-34 & 35-39 & $40-44$ & $45-49$ \\
\hline 2014 & $\begin{array}{c}27.7 \\
(17.7,37.8)\end{array}$ & $\begin{array}{c}193.3 \\
(184.7,201.9)\end{array}$ & $\begin{array}{c}149.1 \\
(141.4,156.8)\end{array}$ & $\begin{array}{c}60.2 \\
(53.2,67.3)\end{array}$ & $\begin{array}{c}19.6 \\
(11.9,27.4)\end{array}$ & $\begin{array}{c}6.3 \\
(0,9.2)\end{array}$ & $\begin{array}{c}2.3 \\
(0,5.7)\end{array}$ \\
\hline 2015 & $\begin{array}{c}26.2 \\
(14.9,37.4)\end{array}$ & $\begin{array}{c}191.9 \\
(181,202.8)\end{array}$ & $\begin{array}{c}146.8 \\
(138.7,154.9)\end{array}$ & $\begin{array}{c}57 \\
(49.4,65.5)\end{array}$ & $\begin{array}{c}16.8 \\
(8.2,25.4)\end{array}$ & $\begin{array}{c}5 \\
(0,8.1)\end{array}$ & $\begin{array}{c}1.9 \\
(0,5.4)\end{array}$ \\
\hline 2016 & $\begin{array}{c}24.6 \\
(12.2,36.9)\end{array}$ & $\begin{array}{c}190.5 \\
(177.6,203.3)\end{array}$ & $\begin{array}{c}144.4 \\
(136,152.9)\end{array}$ & $\begin{array}{c}53.7 \\
(45.6,61.8)\end{array}$ & $\begin{array}{c}14 \\
(4.6,23.4)\end{array}$ & $\begin{array}{c}3.8 \\
(0,7)\end{array}$ & $\begin{array}{c}1.5 \\
(0,5)\end{array}$ \\
\hline 2017 & $\begin{array}{c}23 \\
(9.6,36.4)\end{array}$ & $\begin{array}{c}189.1 \\
(174.4,203.7)\end{array}$ & $\begin{array}{c}142.1 \\
(133.3,150.9)\end{array}$ & $\begin{array}{c}50.4 \\
(41.8,59)\end{array}$ & $\begin{array}{c}11.2 \\
(1,21.3)\end{array}$ & $\begin{array}{c}2.5 \\
(0,5.9)\end{array}$ & $\begin{array}{c}1.1 \\
(0,4.7)\end{array}$ \\
\hline 2018 & $\begin{array}{c}21.4 \\
(7,35.8)\end{array}$ & $\begin{array}{c}187.6 \\
(171.4,203.9)\end{array}$ & $\begin{array}{c}139.8 \\
(130.6,148.9)\end{array}$ & $\begin{array}{c}47.2 \\
(38.1,56.2)\end{array}$ & $\begin{array}{c}8.4 \\
(0,19.3)\end{array}$ & $\begin{array}{c}1.2 \\
(0,4.8)\end{array}$ & $\begin{array}{c}0.7 \\
(0,4.3)\end{array}$ \\
\hline 2019 & $\begin{array}{c}19.8 \\
(4.4,35.2)\end{array}$ & $\begin{array}{c}186.2 \\
(168.4,204.1)\end{array}$ & $\begin{array}{c}137.4 \\
(128,146.9)\end{array}$ & $\begin{array}{c}43.9 \\
(34.3,53.5)\end{array}$ & $\begin{array}{c}5.6 \\
(0,17.2)\end{array}$ & $\begin{array}{c}0 \\
(0,3.6)\end{array}$ & $\begin{array}{c}0.2 \\
(0,4)\end{array}$ \\
\hline 2020 & $\begin{array}{c}18.2 \\
(1.9,34.6)\end{array}$ & $\begin{array}{c}184.8 \\
(165.9,204.1)\end{array}$ & $\begin{array}{c}135.1 \\
(125.3,144.9)\end{array}$ & $\begin{array}{c}40.6 \\
(30.6,50.7)\end{array}$ & $\begin{array}{l}2.7 \\
(0,15)\end{array}$ & $\begin{array}{c}0 \\
(0,2.5)\end{array}$ & $\begin{array}{c}0 \\
(0,3.6)\end{array}$ \\
\hline
\end{tabular}

Table 3: Forecast values of ASFR along with $95 \%$ prediction interval for rural India

\begin{tabular}{|c|c|c|c|c|c|c|c|}
\hline Forecast (Rural) & 15-19 & $20-24$ & $25-29$ & $30-34$ & 35-39 & $40-44$ & 45-49 \\
\hline 2014 & $\begin{array}{c}28 \\
(14.1,41.9)\end{array}$ & $\begin{array}{c}213.3 \\
(201.7,224.8)\end{array}$ & $\begin{array}{c}154.7 \\
(147.3,162)\end{array}$ & $\begin{array}{c}65 \\
(56.9,73)\end{array}$ & $\begin{array}{c}24.7 \\
(18.2,31.2)\end{array}$ & $\begin{array}{c}9 \\
(4.4,13.6)\end{array}$ & $\begin{array}{c}2.4 \\
(0,8.9)\end{array}$ \\
\hline 2015 & $\begin{array}{c}26.1 \\
(10.7,41.5)\end{array}$ & $\begin{array}{c}212.1 \\
(197.2,227.1)\end{array}$ & $\begin{array}{c}152.1 \\
(144.2,160)\end{array}$ & $\begin{array}{c}61.6 \\
(52.8,70.3)\end{array}$ & $\begin{array}{c}22 \\
(14.9,29.1)\end{array}$ & $\begin{array}{c}7.7 \\
(2.8,12.6)\end{array}$ & $\begin{array}{c}1.9 \\
(0,8.5)\end{array}$ \\
\hline 2016 & $\begin{array}{c}24.2 \\
(7.4,41.1)\end{array}$ & $\begin{array}{c}211 \\
(193.2,228.9)\end{array}$ & $\begin{array}{c}149.5 \\
(141,157.9)\end{array}$ & $\begin{array}{c}58.2 \\
(48.8,67.6)\end{array}$ & $\begin{array}{c}19.3 \\
(11.6,27)\end{array}$ & $\begin{array}{c}6.3 \\
(1.2,11.5)\end{array}$ & $\begin{array}{c}1.3 \\
(0,8.1)\end{array}$ \\
\hline 2017 & $\begin{array}{c}22.4 \\
(4.2,40.6)\end{array}$ & $\begin{array}{c}209.9 \\
(189.5,230.3)\end{array}$ & $\begin{array}{c}146.8 \\
(137.9,155.8)\end{array}$ & $\begin{array}{c}54.8 \\
(44.8,64.9)\end{array}$ & $\begin{array}{c}16.6 \\
(8.4,24.9)\end{array}$ & $\begin{array}{c}5 \\
(0,10.4)\end{array}$ & $\begin{array}{c}0.7 \\
(0,7.7)\end{array}$ \\
\hline 2018 & $\begin{array}{c}20.5 \\
(1,40)\end{array}$ & $\begin{array}{c}208.8 \\
(186,231.6)\end{array}$ & $\begin{array}{c}144.2 \\
(134.8,153.7)\end{array}$ & $\begin{array}{c}51.4 \\
(40.8,62.1)\end{array}$ & $\begin{array}{c}13.9 \\
(5.1,22.7)\end{array}$ & $\begin{array}{c}3.6 \\
(0,9.4)\end{array}$ & $\begin{array}{c}0.1 \\
(0,7.3)\end{array}$ \\
\hline 2019 & $\begin{array}{c}18.6 \\
(0,39.4)\end{array}$ & $\begin{array}{c}207.7 \\
(182.6,232.7)\end{array}$ & $\begin{array}{c}141.6 \\
(131.7,151.5)\end{array}$ & $\begin{array}{c}48.1 \\
(36.8,59.3)\end{array}$ & $\begin{array}{c}11.2 \\
(1.9,20.5)\end{array}$ & $\begin{array}{c}2.3 \\
(0,8.3)\end{array}$ & $\begin{array}{c}0 \\
(0,6.9)\end{array}$ \\
\hline 2020 & $\begin{array}{c}16.7 \\
(0,38.8)\end{array}$ & $\begin{array}{c}206.6 \\
(179.4,233.7)\end{array}$ & $\begin{array}{c}139 \\
(128.6,149.4)\end{array}$ & $\begin{array}{c}44.7 \\
(32.8,56.6)\end{array}$ & $\begin{array}{c}8.5 \\
(0,18.3)\end{array}$ & $\begin{array}{c}1 \\
(0,7.2)\end{array}$ & $\begin{array}{c}0 \\
(0,6.5)\end{array}$ \\
\hline
\end{tabular}

Table 4: Forecast values of ASFR along with $95 \%$ prediction interval for urban India

\begin{tabular}{|c|c|c|c|c|c|c|c|}
\hline Forecast (Urban) & $15-19$ & $20-24$ & $25-29$ & $30-34$ & 35-39 & $40-44$ & $45-49$ \\
\hline 2014 & $\begin{array}{c}13.5 \\
(5.4,21.6)\end{array}$ & $\begin{array}{c}141.1 \\
(130.8,151.3)\end{array}$ & $\begin{array}{c}126.8 \\
(117,136.6)\end{array}$ & $\begin{array}{c}52.9 \\
(44.5,61.4)\end{array}$ & $\begin{array}{c}13.9 \\
(7.9,20)\end{array}$ & $\begin{array}{c}3 \\
(0,7.7)\end{array}$ & $\begin{array}{c}1.1 \\
(0,4.3)\end{array}$ \\
\hline 2015 & $\begin{array}{c}12.1 \\
(3.3,20.9)\end{array}$ & $\begin{array}{c}139.4 \\
(126.1,152.7)\end{array}$ & $\begin{array}{c}124.6 \\
(113.7,135.6)\end{array}$ & $\begin{array}{c}50.4 \\
(40.2,60.5)\end{array}$ & $\begin{array}{c}12.2 \\
(5.3,19)\end{array}$ & $\begin{array}{c}2.1 \\
(0,7.3)\end{array}$ & $\begin{array}{c}0.7 \\
(0,4.2)\end{array}$ \\
\hline 2016 & $\begin{array}{c}10.7 \\
(1.3,20.1)\end{array}$ & $\begin{array}{c}137.7 \\
(121.9,153.6)\end{array}$ & $\begin{array}{c}122.4 \\
(110.4,134.5)\end{array}$ & $\begin{array}{c}47.8 \\
(36.1,59.5)\end{array}$ & $\begin{array}{c}10.4 \\
(2.8,18.1)\end{array}$ & $\begin{array}{c}1.3 \\
(0,6.9)\end{array}$ & $\begin{array}{c}0.4 \\
(0,4.1)\end{array}$ \\
\hline 2017 & $\begin{array}{c}9.3 \\
(0,19.4)\end{array}$ & $\begin{array}{c}136.1 \\
(117.9,154.2)\end{array}$ & $\begin{array}{c}120.2 \\
(107.1,133.4)\end{array}$ & $\begin{array}{c}45.2 \\
(32.2,58.3)\end{array}$ & $\begin{array}{c}8.6 \\
(0.3,17)\end{array}$ & $\begin{array}{c}0.4 \\
(0,6.5)\end{array}$ & $\begin{array}{c}0.1 \\
(0,4)\end{array}$ \\
\hline 2018 & $\begin{array}{c}7.9 \\
(0,18.6)\end{array}$ & $\begin{array}{c}134.4 \\
(114.2,154.7)\end{array}$ & $\begin{array}{c}118 \\
(103.9,132.2)\end{array}$ & $\begin{array}{c}42.7 \\
(28.3,57.1)\end{array}$ & $\begin{array}{c}6.9 \\
(0,16)\end{array}$ & $\begin{array}{c}0 \\
(0,6.1)\end{array}$ & $\begin{array}{c}0 \\
(0,3.9)\end{array}$ \\
\hline 2019 & $\begin{array}{c}6.5 \\
(0,17.8)\end{array}$ & $\begin{array}{c}132.8 \\
(110.5,155)\end{array}$ & $\begin{array}{c}115.8 \\
(100.7,131)\end{array}$ & $\begin{array}{c}40.1 \\
(24.5,55.7)\end{array}$ & $\begin{array}{c}5.1 \\
(0,14.9)\end{array}$ & $\begin{array}{c}0 \\
(0,5.7)\end{array}$ & $\begin{array}{c}0 \\
(0,3.8)\end{array}$ \\
\hline 2020 & $\begin{array}{c}5.1 \\
(0,17)\end{array}$ & $\begin{array}{c}131.1 \\
(107,155.2)\end{array}$ & $\begin{array}{c}113.6 \\
(97.5,129.7)\end{array}$ & $\begin{array}{c}37.5 \\
(20.7,54.4)\end{array}$ & $\begin{array}{c}3.3 \\
(0,13.8)\end{array}$ & $\begin{array}{c}0 \\
(0,5.2)\end{array}$ & $\begin{array}{c}0 \\
(0,3.7)\end{array}$ \\
\hline
\end{tabular}

In Fig. 4 it is clear that in case of whole India the percentage variation explained due to the first two components are 96 percent and three percent, respectively. Also, the percentage variation explained due to the first two basis functions for rural region are 97 percent and two percent respectively and for urban region are 93 percent and five percent respectively. Hence to fit FTS model only first two basis functions are sufficient to explain about 99 percent of the total variability for total and rural region and 98 percent for urban region which account for the almost entire variability in age-specific fertility rates, leaving only one percent and two percent unexplained.

In Fig. 5, plots display the components (the plots of the mean function, the first two basis functions and their corresponding coefficients of FTS model) for India (total) and Fig. 6 and Fig. 7 visualize the components for rural and urban region respectively. The mean function basically reflects the fertility trend over different ages and the basis functions model different movements in different age ranges; the first basis function in first two cases (Fig. 5 and Fig. 6) model the middle-aged pregnancy at around age 30 i.e. the birth rate of middle age group while the second basis function stands for the early-aged i.e. before 25 and slightly older-aged pregnancy i.e. after 40 and for urban India (Fig. 7) first and second basis functions model younger age group pregnancy and older age group pregnancy. Accordingly, the coefficient functions associated with basis functions tell the social effects. In case of rural India the coefficient of the first component declining fast which is relatively slow in the coefficient of second component in case of urban India that means there is a notable decrease in middle-aged pregnancy in rural India and the decrement is less in urban India. Also one can see major changes occur in younger age-groups in rural India and in older age-groups in urban India. If we do intergroup comparison among each region, while middle age-groups (30-34, 35-39) declining fluently, younger age-groups (15-19, 2024 before 1990) show slight increment in rural India and also after forecasting teen age pregnancy is becoming higher may be because of lack of education. In urban India although the age-group 20-24 has a sudden jump in between 1980-90 but overall youngaged pregnancy are declining comparatively faster than old-aged pregnancy. In Fig. 5, Fig. 6 and Fig. 7 ten year forecasts of the 
coefficients based on Random Walk models are shown along with 95 percent prediction interval.

Combining the forecast coefficients with the estimated basis functions, yield forecasts of the fertility curves for 2014-2023. Table 2, 3 and 4 above calculate and Fig. 8 displays the forecasts of ASFR of total, rural and urban fertility for the next ten years including observed ASFR. Both the available data and the forecasted values display the continuous decrement in fertility rates for all seven age groups but relatively slow in two extreme points approximately before 18 and 43+. Also forecasts follow the previous fertility trend i.e. there is a rapid decline in older age groups (30-34, 35-39 and 40-44) than middle aged (20-24 and 25-29) women in case of total and rural in India. Forecasts also follow the huge variability in older ages for total and rural and middle ages for urban.
Forecasts of ASFR in India (Total)

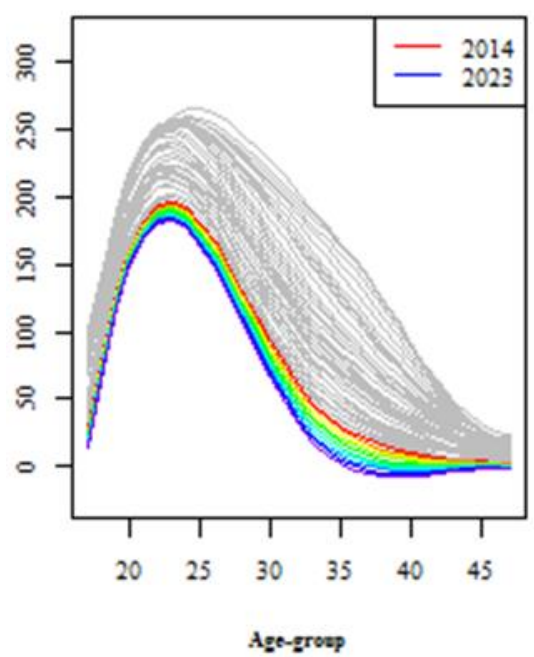

Forecasts of ASFR in India (Rural)

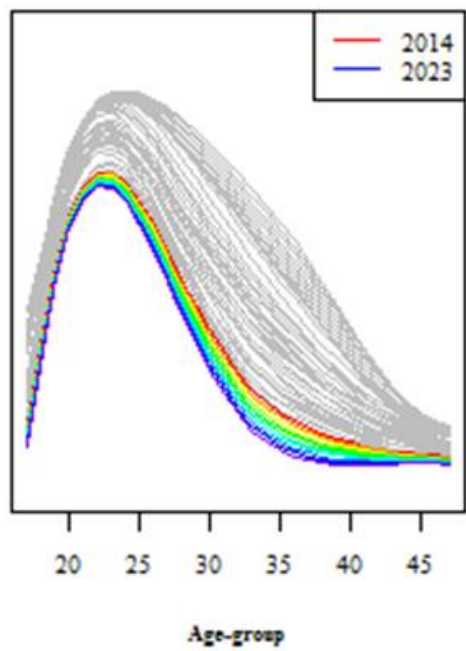

Forecasts of ASFR in India (Urban)

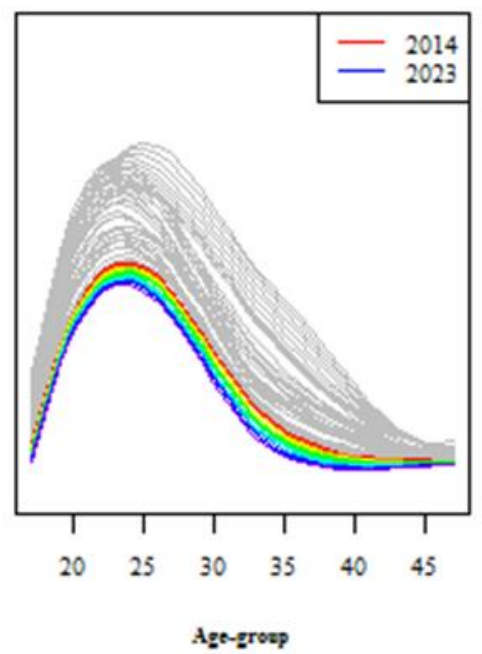

Figure 8: ASFR forecasts for 2014 to 2023 (color 'rainbow') based on the historical ASFR (Total, rural \& urban) data from 1971 to 2013 (color 'grey').

\section{Concluding Remarks}

India is currently passing through the third phase of demographic transition with a substantial accelerated fertility decline in almost all the parts of the country. Yet, evidence on convergence in fertility is very limited and the future course of fertility decline in the highly populous areas of the country and in the most fertile age categories of women will dictate whether the country is going to move to the fourth phase of replacement fertility.

While there have been numerous studies depicting divergence of regional and state level fertility transitions, there are limited or no studies that have examined extensively the change in the age pattern of fertility across reproductive age groups of women in India. To understand the evolution of the process of fertility transition, it is important to consider changes in the age pattern of fertility along with the regional and state level differentials. The primary objective of this paper is to understand the role of temporal variability in the fertility level among the various age categories of Indian women in dictating the future course of fertility decline.

The present study observes that the rate of decline in fertility across the five year reproductive age groups varied widely during the period 1971-2013. In 1971, all women below 40 years of age had started with a high level of ASFR more than 100 per thousand. While rural India was seen with similar but higher levels of ASFR, urban region of the country had ASFR level below 100 per thousand in 1971 for all the aforesaid age categories including the age group 15-19. During the period 1971-2013, ASFR for the age group 15-19 for total and rural India declined from 101 to 28 per thousand and 111 to 32 per thousand respectively, that is, by 72 percent and 71 percent respectively. The youngest age group thus experienced the maximum fall during the period followed by the age group 30-34 with 68 percent decline for both total and rural India. On the other hand, only a modest decline was seen in the 20-24 age group, mostly attributable to rise in the age at marriage.

FTSA demonstrates the regional disparities in temporal variations of ASFRs over the study period. While, rural women above 30 years of age had shown wider temporal variability with sharp decline in recent years urban women below 30 years, on the other hand experienced sharper fall in ASFRs. The analysis further confirms that the future trend in fertility of the country will be mostly guided by the rural pattern. The major changes in fertility rates among Indian women dominated by rural representation occur at ages after 30 while women aged 20-24 contribute to the major changes in fertility in the urban parts of the country. Thus, it may be summarized that in the evolutionary process of fertility transition, initiation of fertility decline during early seventies has occur in urban India among the younger women aged below 30 years. Later, a sharp decline in fertility is observed among rural women aged 30 years and above. The demographic transition of India from third phage to the forth phage of replacement of fertility would depend on the pace of decline among the rural women aged below 30 years with postponement of marriage and an increased career pursuit and labour force participation.

\section{Acknowledgement}

The first author acknowledge the University Grant Commission for her financial support through Non-NET fellowship with award No.F.24-25/DSW/2012/1970. 


\section{Appendix}

Table A1: Estimated ASFR for missing years in India (Total)

\begin{tabular}{cccccccc} 
Total & $\mathbf{1 5 - 1 9}$ & $\mathbf{2 0 - 2 4}$ & $\mathbf{2 5 - 2 9}$ & $\mathbf{3 0 - 3 4}$ & $\mathbf{3 5 - 3 9}$ & $\mathbf{4 0 - 4 4}$ & $\mathbf{4 5 - 4 9}$ \\
\hline $\mathbf{1 9 7 2}$ & 96.4 & 248.1 & 246.4 & 197.6 & 139.9 & 60.0 & 22.0 \\
$\mathbf{1 9 7 3}$ & 91.9 & 247.5 & 242.4 & 193.7 & 137.8 & 58.3 & 19.5 \\
$\mathbf{1 9 7 4}$ & 87.9 & 248.1 & 241.1 & 189.7 & 132.5 & 56.8 & 17.4 \\
$\mathbf{1 9 7 5}$ & 84.8 & 249.1 & 240.5 & 185.3 & 124.9 & 55.2 & 16.1 \\
$\mathbf{1 9 7 7}$ & 82.8 & 248.9 & 234.8 & 172.9 & 107.2 & 51.0 & 16.6 \\
$\mathbf{1 9 7 8}$ & 84.0 & 247.6 & 230.1 & 166.4 & 99.8 & 48.6 & 18.1 \\
$\mathbf{1 9 7 9}$ & 85.9 & 246.5 & 226.9 & 162.4 & 95.9 & 46.4 & 19.5 \\
$\mathbf{1 9 8 2}$ & 92.4 & 248.1 & 233.4 & 167.4 & 102.5 & 43.3 & 18.3 \\
$\mathbf{1 9 8 3}$ & 93.9 & 249.3 & 230.8 & 161.8 & 97.2 & 42.6 & 16.9 \\
$\mathbf{1 9 8 4}$ & 94.4 & 250.6 & 226.1 & 153.5 & 89.4 & 41.5 & 15.6 \\
$\mathbf{1 9 8 5}$ & 93.6 & 251.8 & 220.7 & 145.1 & 82.2 & 40.0 & 14.8 \\
\hline
\end{tabular}

Table A2: Estimated ASFR for missing years in Rural India

\begin{tabular}{cccccccc} 
Rural & $\mathbf{1 5 - 1 9}$ & $\mathbf{2 0 - 2 4}$ & $\mathbf{2 5 - 2 9}$ & $\mathbf{3 0 - 3 4}$ & $\mathbf{3 5 - 3 9}$ & $\mathbf{4 0 - 4 4}$ & $\mathbf{4 5 - 4 9}$ \\
\hline $\mathbf{1 9 7 2}$ & 99.1 & 261.3 & 259.7 & 207.3 & 143.3 & 68.3 & 23.0 \\
$\mathbf{1 9 7 3}$ & 91.5 & 261.4 & 257.6 & 202.7 & 139.2 & 67.2 & 20.5 \\
$\mathbf{1 9 7 4}$ & 87.3 & 261.2 & 255.4 & 198.5 & 135.0 & 65.1 & 18.9 \\
$\mathbf{1 9 7 5}$ & 86.0 & 260.8 & 253.0 & 194.6 & 130.9 & 62.3 & 17.8 \\
$\mathbf{1 9 7 7}$ & 89.7 & 259.6 & 248.0 & 187.4 & 122.6 & 55.3 & 17.2 \\
$\mathbf{1 9 7 8}$ & 93.2 & 259.2 & 245.9 & 184.4 & 118.8 & 51.8 & 17.6 \\
$\mathbf{1 9 7 9}$ & 96.4 & 259.2 & 244.4 & 182.0 & 115.6 & 49.2 & 18.4 \\
$\mathbf{1 9 8 0}$ & 98.4 & 259.8 & 243.9 & 180.6 & 113.5 & 47.9 & 19.9 \\
$\mathbf{1 9 8 2}$ & 95.5 & 263.6 & 247.1 & 181.1 & 112.9 & 50.8 & 24.5 \\
$\mathbf{1 9 8 3}$ & 92.7 & 265.9 & 248.4 & 180.3 & 111.9 & 53.2 & 26.1 \\
$\mathbf{1 9 8 5}$ & 97.6 & 266.2 & 238.4 & 164.0 & 97.1 & 48.8 & 20.8 \\
\hline
\end{tabular}

Table A3: Estimated ASFR for missing years in Urban India

\begin{tabular}{cccccccc} 
Urban & $\mathbf{1 5 - 1 9}$ & $\mathbf{2 0 - 2 4}$ & $\mathbf{2 5 - 2 9}$ & $\mathbf{3 0 - 3 4}$ & $\mathbf{3 5 - 3 9}$ & $\mathbf{4 0 - 4 4}$ & $\mathbf{4 5 - 4 9}$ \\
\hline $\mathbf{1 9 7 2}$ & 66.0 & 217.2 & 220.4 & 154.3 & 92.4 & 33.2 & 12.5 \\
$\mathbf{1 9 7 3}$ & 66.3 & 218.4 & 213.6 & 150.0 & 87.9 & 31.8 & 10.5 \\
$\mathbf{1 9 7 4}$ & 66.1 & 218.0 & 207.6 & 145.0 & 83.3 & 30.6 & 9.2 \\
$\mathbf{1 9 7 5}$ & 65.5 & 216.3 & 202.3 & 139.6 & 78.5 & 29.7 & 8.5 \\
$\mathbf{1 9 7 7}$ & 63.5 & 210.6 & 193.3 & 128.0 & 68.8 & 28.3 & 8.5 \\
$\mathbf{1 9 7 8}$ & 62.3 & 207.0 & 189.9 & 122.7 & 64.5 & 27.7 & 9.0 \\
$\mathbf{1 9 7 9}$ & 60.9 & 203.2 & 187.6 & 118.7 & 61.2 & 26.9 & 9.3 \\
$\mathbf{1 9 8 0}$ & 59.5 & 199.1 & 186.5 & 116.8 & 59.6 & 25.9 & 9.5 \\
$\mathbf{1 9 8 2}$ & 56.8 & 191.3 & 188.8 & 121.4 & 62.6 & 22.4 & 8.1 \\
$\mathbf{1 9 8 3}$ & 56.5 & 190.4 & 189.7 & 123.2 & 63.8 & 20.3 & 6.8 \\
$\mathbf{1 9 8 5}$ & 61.3 & 206.1 & 180.3 & 104.0 & 50.1 & 17.4 & 4.7 \\
\hline
\end{tabular}

\section{References}

[1] Besse, P. C and Cardot, H., "Autoregressive Forecasting of Some Functional Climatic Variations", Scandinavian Journal of Statistics, Vol.27, No.4, (2000), pp.673-687. http://empslocal.ex.ac.uk/people/staff/dbs202/publications/2000/bes se.pdf

[2] Box, G. E. P. and Jenkins, G. M., Time Series Analysis: Forecasting and Control, Holden-Day: Wiley Series in Probability and Statistics, (1976).

[3] Chakrabarty, T. K., "Forecasting rate of decline in infant mortality in South Asia using random walk approximation", International Journal of Statistics in Medical Research, Vol.3, No.3, (2014), pp.282-290. http://dx.doi.org/10.6000/1929-6029.2014.03.03.7

[4] Chakrabarty, T. K. and Deb, M., "Is India on the Path to Replacement Fertility soon? Exploring the Role of Rural-Urban Differential Pace and Timing of Fertility Decline", (2015). Forthcoming.

[5] Ferraty, F. and Vieu, P., Nonparametric functional data analysis: theory and practice, Springer, New York, 2006.

[6] Green, P. and Silverman, B., Nonparametric Regression and Generalized Linear Models: A Roughness Penalty Approach, Chapman and Hall, (1994).

[7] H“ormann, S. and Kokoszka, P., "Weakly dependent functional data", The Annals of Statistics, Vol.38, No.3, (2010), pp.1845-1884. http://projecteuclid.org/euclid.aos/1269452656

[8] Hyndman, R. J. and Ullah, M. S., "Robust forecasting of mortality and fertility rates: a functional data approach", Computational Sta- tistics and Data Analysis, Vol.51, No.10, (2007), pp.4942-4956. http://www.sciencedirect.com/science/article/pii/S01679473060024 $\underline{53}$

[9] Hyndman, R. J. and Booth, H., "Stochastic population forecasts using functional data models for mortality, fertility and migration", International Journal of Forecasting, Vol.24, No.3, (2008), pp.323342.

http://www.sciencedirect.com/science/article/pii/S01679473060024 $\underline{53}$

[10] Hyndman, R. J. and Shang, H. L., "Forecasting functional time series", Journal of the Korean Statistical Society, Vol.38, No.3, (2009),

pp.199-221. http://www.sciencedirect.com/science/article/pii/S12263192090003 $\frac{98}{1}$

[11] Hyndman, R. J. and Shang, H. L., "Rainbow plots, bagplots, and boxplots for functional data", Journal of Computational and Graphical Statistics, Vol.19, No.1, (2010), pp.29-45. http://www.tandfonline.com/doi/abs/10.1198/jcgs.2009.08158

[12] Ramsay, J. and Dalzell, C. J., "Some tools for functional data analysis", Journal of the Royal Statistical Society. Series B, Vol.53, No.3, (1991), pp.539-572. http://www.jstor.org/stable/2345586?seq=1\#page_scan_tab_content $\underline{\mathrm{s}}$

[13] Ramsay, J. O. and Silverman, B. W., Functional Data Analysis, Springer, New York, 1997.

[14] Ramsay, J. O. and Silverman, B.W., Applied Functional Data Analysis, Springer, New York, 2002. 
[15] Ramsay, J. O. and Silverman, B. W., Functional Data Analysis, Second edition, Springer, New York, 2005.

[16] Retherford, R. D. and Mishra V. K., "An Evaluation of Recent Estimates of Fertility Trends in India", National Family Health Survey Subject Reports, Vol.19, Mumbai: International Institute for Population Sciences; Honolulu: East-West Center, 2001. http://scholarspace.manoa.hawaii.edu/bitstream/handle/10125/3473 /NFHSsubjrpt019.pdf?sequence $=1$

[17] RGI (Registrar General of India). Compendium of India's Fertility and Mortality Indicators, 1971-2013: Based on the Sample Registration System, New Delhi. Office of the Registrar General. http://censusindia.gov.in

[18] RGI (Registrar General of India). Sample Registration System annual report 49, New Delhi. Office of the Registrar General, 2014. http://censusindia.gov.in

[19] Shang, H. L., "rainbow: an R package for visualizing functional time series", The $R$ Journal, Vol.3, No.2, (2011), pp.54-59. https://journal.r-project.org/archive/2011-2/RJournal 20112_Lin Shang.pdf

[20] Shang, H. L., "ftsa: An R Package for Analyzing Functional Time Series", The $R$ Journal, Vol.5, No.1, (2013), pp.64-72. https://journal.rproject.org/archive/2013-1/shang.pdf

[21] Shang, H. L. and Hyndman, R. J., "Nonparametric time series forecasting with dynamic updating", Mathematics and Computers in Simulation, Vol.81, No.7, (2011), pp.1310-1324 http://www.sciencedirect.com/science/article/pii/S03784754100014 $\underline{5 X}$

[22] Spoorenberg, T. and Dommaraju, P., "Regional Fertility Transition in India: An Analysis Using Synthetic Parity Progression Ratios", International Journal of Population Research, Vol.2012, (2012), pp.1-20. http://dx.doi.org/10.1155/2012/358409

[23] Yasmeen, F., Waseem, H. F. and Mahmood, Z., "An FDA Approach to Forecast Age-Specific Fertility Rates of Pakistan RegionWise", Computer Science and Applications, Vol.1, No.6, (2014), pp.341-348. http://dx.doi.org/10.1155/2012/358409 